\title{
Honokiol induces apoptotic cell death by oxidative burst and mitochondrial hyperpolarization of bladder cancer cells
}

\author{
CHI-HAO HSIAO ${ }^{1-3}$, CHIH-JUNG YAO ${ }^{4,5}$, GI-MING LAI ${ }^{4,5}$, LIANG-MING LEE ${ }^{1,2}$, \\ JACQUELINE WHANG-PENG ${ }^{4,5}$ and PING-HSIAO SHIH $^{6}$
}

\author{
${ }^{1}$ Department of Urology, Wan Fang Hospital, Taipei 11696; ${ }^{2}$ Department of Urology, School of Medicine, \\ College of Medicine; ${ }^{3}$ Graduate Institute of Clinical Medicine, College of Medicine, Taipei 11031; ${ }^{4}$ Cancer Center, \\ Wan Fang Hospital, Taipei 11696; ${ }^{5}$ Center of Excellence for Cancer Research, Taipei Medical University, \\ Taipei 11031; ${ }^{6}$ Center for Cell Therapy, Department of Medical Research, \\ China Medical University Hospital, Taichung 40447, Taiwan R.O.C.
}

Received October 1,2018; Accepted March 7, 2019

DOI: $10.3892 / \mathrm{etm} .2019 .7419$

\begin{abstract}
Bladder cancer is one of the most common types of malignant tumor worldwide. Current treatments, including chemo-/radiotherapy, only have limited efficacy on bladder cancer progression. Honokiol is an active component of Magnolia officinalis with multiple biological effects that may provide promising health benefits. In the present study, the anti-cancer properties of honokiol against bladder cancer cells were investigated by flow cytometric analysis. The results revealed that honokiol exhibited significant anti-proliferative effects on bladder cancer cell lines, particularly on BFTC-905 human transitional cell carcinoma cells. Furthermore, honokiol at low doses $(\leq 25 \mu \mathrm{M})$ induced cell cycle arrest in $\mathrm{G}_{0} / \mathrm{G}_{1}$ phase, while it induced significant apoptotic cell death at high doses $(\geq 50 \mu \mathrm{M} ; \mathrm{P}<0.05$ ). Furthermore, a significant accumulation of reactive oxygen species was identified in honokiol-treated cells. In addition, honokiol induced hyperpolarization of the mitochondrial membrane, which may lead to mitochondrial dysfunction. Finally, caspase-3/7 activation was identified in high-dose honokiol-treated bladder cancer cells. These results suggest that honokiol induces apoptosis via the mitochondrial pathway and honokiol-containing traditional herbal remedies may have a potential clinical application in the treatment of bladder cancer.
\end{abstract}

Correspondence to: Dr Ping-Hsiao Shih, Center for Cell Therapy, Department of Medical Research, China Medical University Hospital, 2 Yu-De Road, Taichung 40447, Taiwan R.O.C.

E-mail:phs1027@gmail.com

Abbreviations: SRB, sulforhodamine B; PI, propidium iodide; $\mathrm{DCFH}_{2}$-DA, 2',7'-dichlorodihydrofluorescein diacetate; DiOC6, 3,3'-dihexyloxacarbocyanine iodide; ROS, reactive oxygen species

Key words: magnolia officinalis, honokiol, bladder cancer, flow cytometry, apoptosis, oxidative stress, mitochondrial membrane hyperpolarization

\section{Introduction}

Urothelial bladder cancer is the most common type of malignancy of the urinary tract, and its incidence and the number of associated mortalities are increasing. According to the estimates of the American Cancer Society for 2018, bladder cancer is the fourth most common cancer type in men, but is less common in women in the USA (1). Based on the Annual Report of the Taiwan Cancer Registry for 2015, the incidence of bladder cancer cases account for $2.07 \%$ of all cancer cases and $~ 50 \%$ of all urinary tract cancer cases, with $1.93 \%$ bladder cancer-related mortalities (2). Stratified by gender, the incidence of bladder cancer amongst all cancer types ranked 10th and 16th and the mortality rates ranked 12 th and 15 th in males and females, respectively. It has been reported that drinking water contamination and agricultural exposure to arsenic may be associated with the occurrence of bladder cancer (3-5). The southwest coast of Taiwan is an endemic area for bladder cancer with an increased incidence rate due to the contamination of drinking water with arsenic, also causing the symptoms of black foot disease (6). The pathological type of urothelial carcinoma (transitional cell carcinoma) accounts for $\sim 94 \%$ of bladder cancers, and $60-80 \%$ of these tumors are superficial disease and confined to the urothelium or the lamina propria at diagnosis. According to the 2018 National Comprehensive Cancer Network guidelines, total endoscopic resection of visible superficial tumor [transurethral resection (TUR)] may be the only treatment required for low-grade pTaG1 low-grade papillary tumors (7). However, tumor recurrence is a major obstacle in patients with higher-grade Ta and $\mathrm{T} 1$ lesions. At 1 year post-TUR, $20 \%$ of patients with low-risk and $40 \%$ of those with medium-risk disease have developed tumor recurrence. Patients with high-risk disease have an even greater recurrence rate of $>90 \%$ at $1-2$ years following TUR. In order to prevent local recurrence, the most commonly used therapeutic approach is intravesical instillation, whereby the agents are instilled into the bladder to delay or prevent tumor recurrence (8). Chemoradiation-based bladder preservation therapy is currently an alternative option for non-metastatic muscle-invasive bladder cancer patients (9). However, the 
current treatment strategies have limited efficacy with regards to inhibiting bladder cancer progression.

Chinese herbal medicines have been widely used as traditional and functional remedies in oriental medicine for thousands of years. Magnolia officinalis, also named Houpo in Chinese or Saiboku-tu in Japanese, is an ancient genus mainly distributed in Southeast Asia and Eastern North America and is known to improve allergic and asthmatic reactions $(10,11)$. Magnolia has been reported to contain several biologically active components, including magnolol, honokiol (International Union of Pure and Applied Chemistry name, 5,3'-diallyl-2,4'-dihydroxybiphenyl), 4- $O$-methylhonokiol, obovatol and certain other neolignan compounds, which have numerous and diverse actions (12). Honokiol is a biphenolic bioactive component of the bark of Magnolia, and it has been indicated to have multifunctional activities, including anti-oxidant, anti-inflammatory and chemopreventive effects $(13,14)$.

It has been reported that honokiol has anti-cancer effects against glioblastoma multiforme, as well as head and neck, lung, breast, stomach and colorectal cancers, and exerts synergistic effects in combination with chemotherapy for cancer treatment (15-19). However, only a small amount of evidence is available for bladder cancer. Previous studies suggested that honokiol is a potential agent against bladder cancer cell invasion and epithelial-to-mesenchymal transition (20); however, the capacity of honokiol to induce cell death and the underlying mechanisms remain unknown. In the present study, it was indicated that honokiol induced obvious reactive oxygen species (ROS) accumulation and transient hyperpolarization of the mitochondrial membrane, which resulted in cell cycle arrest and further led to apoptotic cell death. These pre-clinical data indicate that honokiol-based novel intravesical remedies have promising potential to be applied for bladder cancer treatment in the future.

\section{Materials and methods}

Cells and materials. Honokiol, sulforhodamine B (SRB), dimethyl sulfoxide (DMSO), trichloroacetic acid (TCA) and 3,3'-dihexyloxacarbocyanine iodide (DiOC6) were purchased from Sigma-Aldrich (Merck KGaA, Darmstadt, Germany). A fluorescein isothiocyanate (FITC) Annexin V Apoptosis Detection kit (cat. no. 556547) was obtained from BD Biosciences (Franklin Lakes, NJ, USA). 2',7'-dichlorodihydrofluorescein diacetate $\left(\mathrm{DCFH}_{2}-\mathrm{DA}\right)$ was purchased from Thermo Fisher Scientific, Inc. (Waltham, MA, USA). The Bioresource Collection and Research Center (BCRC; Food Industry Research and Development Institute, Hsin Chu, Taiwan) provided the human bladder cancer cell lines, including T24 (BCRC no. 60062), BFTC-905 (BCRC no. 60068) and TSGH 8301 (BCRC no. 60145). The other reagents were of high grade and purchased from commercial companies.

Cell culture. T24 bladder cancer cells were cultured in McCoy's 5a basal medium supplemented with $1.5 \mathrm{~g} / 1$ sodium bicarbonate, $100 \mathrm{U} / \mathrm{ml}$ penicillin/streptomycin and 10\% fetal bovine serum (FBS; all Gibco; Thermo Fisher Scientific, Inc.). BFTC-905 and TSGH 8301 bladder cancer cells were cultured in RPMI-1640 medium (Gibco; Thermo Fisher Scientific,
Inc.) supplemented with $1.5 \mathrm{~g} / 1$ sodium bicarbonate, $100 \mathrm{U} / \mathrm{ml}$ penicillin/streptomycin and $15 \%$ or $10 \%$ FBS, respectively. All cells were maintained at $37^{\circ} \mathrm{C}$ in a $5 \% \mathrm{CO}_{2}$-humidified incubator (Steri-Cycle $\mathrm{CO}_{2}$ incubator; Thermo Fisher Scientific, Inc.).

SRB cell viability assay. The cytotoxic effects of honokiol were determined using a modified SRB colorimetric drug-screening assay (21). In brief, cells were seeded into 96-well flat-bottomed plates (1,500 cells/well) in $200 \mu \mathrm{l}$ medium. After $24-\mathrm{h}$ incubation, the cells were treated with different concentrations of honokiol $(0,25,50$ and $100 \mu \mathrm{M}$; stock solution in DMSO, final DMSO concentration was $\leq 0.05 \%$ ), followed by further incubation for 3 days. Subsequently, the medium was aspirated and the cells were fixed by addition of $100 \mu 110 \%$ TCA for $2 \mathrm{~h}$ at $4^{\circ} \mathrm{C}$. The plates were washed five times with water to remove TCA and air-dried for at least $1 \mathrm{~h}$. This was followed by staining with $200 \mu \mathrm{l}$ of $0.065 \% \mathrm{SRB}$ for $30 \mathrm{~min}$ at room temperature, washing for five times with $1 \%$ acetic acid to remove any unbound dye and subsequent drying in a chemical hood. The bound dye was dissolved in $200 \mu 110 \mathrm{mM}$ Tris base (pH 10.5). The absorbance was read using a spectrophotometer (SpectraMax M2 ${ }^{\text {e }}$ Molecular Devices, Sunnyvale, CA, USA) at $570 \mathrm{~nm}$. Cell morphology was examined under a light microscope (Olympus CKX41; Olympus, Tokyo, Japan).

Cell cycle analysis. Cells were treated with various concentrations $(0,12.5,25,50$ and $75 \mu \mathrm{M})$ of honokiol for $72 \mathrm{~h}$. The floating and adherent cells were then harvested prior to centrifugation at $600 \mathrm{x} \mathrm{g}$ for $10 \mathrm{~min}$ at $4^{\circ} \mathrm{C}$. Subsequently, cells were washed twice with cold PBS and fixed with $70 \%$ ethanol and stored immediately at $4^{\circ} \mathrm{C}$ overnight. Following incubation, ethanol was removed and cells were incubated with a solution containing $25 \mu \mathrm{g} / \mathrm{ml}$ PI, $0.5 \%$ Triton X-100 and $0.2 \mathrm{mg} / \mathrm{ml}$ RNase A (Thermo Fisher Scientific, Inc.) for 30 min after washing with cold PBS. A positive control group was established by exposing the cells to ultraviolet radiation for $1 \mathrm{~h}$. Finally, the cells were re-suspended in $500 \mu \mathrm{l} \mathrm{PBS}$ and then analyzed by flow cytometry (BD Accuri ${ }^{\mathrm{TM}}$ C6 Plus; BD Biosciences). Data were collected from 10,000 cells and evaluated by using BD Accuri ${ }^{\text {TM }}$ C6 software (version 1.0; BD Biosciences).

Measurement of intracellular ROS. The cells were treated with various concentrations of honokiol for $24 \mathrm{~h}$. At the end of the incubation, the floating and the adherent cells were harvested and then incubated with $\mathrm{DCFH}_{2}$-DA (final concentration, $20 \mu \mathrm{M}$ ) for $30 \mathrm{~min}$ after washing with cold PBS. Finally, the cells were re-suspended in $500 \mu 1$ PBS and analyzed by flow cytometry (BD Biosciences). The data for 10,000 cells were collected and evaluated with BD Accuri ${ }^{\mathrm{TM}}$ C6 software (BD Biosciences).

Annexin V/PI double staining assay. The cells were treated with various concentrations of honokiol for $48 \mathrm{~h}$. At the end of the incubation, the floating and the adherent cells were harvested and then incubated with Annexin V-FITC and PI for $15 \mathrm{~min}$ at $37^{\circ} \mathrm{C}$ in the dark after washing with cold PBS. Finally, the cells were re-suspended in $500 \mu \mathrm{l}$ PBS and then analyzed by flow cytometry (BD Biosciences). A positive control group 
was established by exposing the cells to ultraviolet radiation for $30 \mathrm{~min}$ for adjusting for fluorescence spectral overlap compensation. The data for 10,000 cells were collected and evaluated with BD Accuri ${ }^{\mathrm{TM}}$ C6 software (BD Biosciences).

Mitochondrial membrane potential $\left(\Delta \Psi_{m}\right)$ evaluation. Cells were treated with various concentrations of honokiol for $48 \mathrm{~h}$. At the end of the incubation, the floating and the adherent cells were harvested and then incubated with DiOC6 (final concentration, $40 \mu \mathrm{M}$ ) for $15 \mathrm{~min}$ at $37^{\circ} \mathrm{C}$ in the dark after washing with cold PBS. Finally, the cells were resuspended in $500 \mu \mathrm{l}$ PBS and then analyzed in the FL-1 channel by flow cytometry (BD Biosciences). Data were collected from 10,000 cells and evaluated with BD Accuri ${ }^{\mathrm{TM}}$ C6 software (BD Biosciences).

Caspase 3/7 activity analysis. The activity of caspase-3/7 was assessed using a fluorometric Caspase 3/7 assay kit (cat. no. 556547; Abcam, Cambridge, UK), according to the manufacturer's protocol. The caspase-3/7 assay is based on the detection of cleaved fluorescent DEVD-7-amino-4-trifluoromethyl coumarin (AFC). In brief, the treated cells were re-suspended in $50 \mu$ l chilled cell lysis buffer and incubated on ice for $10 \mathrm{~min}$. Following incubation, $1 \mathrm{ml}$ of $2 \mathrm{X}$ reaction buffer (containing $10 \mu \mathrm{M}$ DTT) was added to each sample and incubated in the dark for $1-2 \mathrm{~h}$ at $37^{\circ} \mathrm{C}$ in a 96-well plate. The fluorescence was measured with a fluorescence reader (SpectraMax M2 ${ }^{\mathrm{e}}$; Molecular Devices) using an excitation wavelength of $400 \mathrm{~nm}$ and an emission wavelength of $505 \mathrm{~nm}$. Fold-increases in caspase-3/7 activity were determined by comparing the results for the treated groups with those of the untreated control and normalized to the respective protein concentration. Total protein was quantified using the Bradford dye-binding method (Bio-Rad Laboratories, Inc., Hercules, CA, USA).

Statistical analysis. All assays were performed as three independent experiments with $n \geq 3$ in each test. Values are expressed as the mean \pm standard error of the mean. Statistically significant differences between treatment group and control group were assessed by one-way analysis of variance followed by Tukey's multiple-comparisons test using Prism 6.1d (GraphPad Software, Inc., La Jolla, CA, USA).

\section{Results}

Honokiol significantly inhibits bladder cancer cell growth. First, the inhibitory effect of honokiol on bladder cancer cells was investigated. The human bladder cancer cell lines T-24 (human transitional cell carcinoma), TSGH-8301 (human urinary bladder carcinoma) and BFTC-905 (human bladder papillary transitional cell carcinoma grade III) were examined. It was revealed that honokiol exhibited a marked cytotoxic effect against all three bladder cancer cell lines, and BFTC-905 cells were more sensitive to honokiol at the lower concentration $\left(25 \mu \mathrm{M} ; \mathrm{IC}_{50}=30 \pm 2.8 \mu \mathrm{M}\right.$ at $72 \mathrm{~h}$ of incubation; Fig. 1A), while no obvious difference in cytotoxicity was observed between the cell lines at high concentrations of honokiol. Of note, DMSO at $0.05 \%$ as the vehicle control did not exert any inhibitory effect on any of the three cell lines. Furthermore, cell morphological observation revealed that honokiol obviously reduced the amount of cells and induced cell detachment after $48 \mathrm{~h}$ of incubation (Fig. 1B). Due to its high sensitivity to honokiol, the subsequent experiments were performed using BFTC-905 as the model cells.

Honokiol induces cell cycle arrest and apoptotic cell death of bladder cancer cells. The effect of honokiol on cell cycle progression was then investigated. It was revealed that low doses of honokiol induced significant cell cycle arrest in $G_{0} / G_{1}$ phase $(\mathrm{P}<0.05)$, with the population in that phase demonstrating an increase from $60 \pm 4.8 \%$ in the control group to $70 \pm 8.4$ and $76 \pm 7.9 \%$ in the groups treated with 12.5 and $25 \mathrm{mM}$ honokiol, respectively, for $72 \mathrm{~h}$ incubation (Fig. 2A and B). Furthermore, the high dose of honokiol increased the population in sub-G1 phase that resembles apoptotic cells $(\mathrm{P}<0.05)$; the sub-G1 phase population increased from $3 \pm 1.8 \%$ in the control group to $38 \pm 3.7$ and $46 \pm 2.8 \%$ following treatment with 50 and $75 \mu \mathrm{M}$ honokiol, respectively, for $72 \mathrm{~h}$ (Fig. 2C).

Apoptotic effect of honokiol on bladder cancer cells. In the present study, the detailed effect of honokiol on apoptotic cell death was assessed. It was revealed that 50 and $75 \mu \mathrm{M}$ honokiol significantly increased the proportion of cells in early apoptosis (Annexin $\mathrm{V}^{+} / \mathrm{PI}^{-}$cells; $19 \pm 5.7$ and $40 \pm 4.8 \%$ ) compared with the control group $(5 \pm 1.8 \%)$, following $48 \mathrm{~h}$ of incubation $(\mathrm{P}<0.05$; Fig. 3). In addition, high-dose honokiol (75 $\mu \mathrm{M})$ significantly induced late apoptotic cell death $(21 \pm 6.7 \%)$ compared with the control group $(3 \pm 2.8 \% ; \mathrm{P}<0.05)$.

Oxidative burst in honokiol-treated cells. The effect of honokiol on the redox status of bladder cancer cells was investigated. It was identified that high-dose honokiol (50 and $75 \mu \mathrm{M}$ ) induced a significant increase in ROS in bladder cancer cells $(140 \pm 13.2$ and $150 \pm 12.3 \%$, respectively) compared with the control group, following $24 \mathrm{~h}$ incubation $(\mathrm{P}<0.05$; Fig. 4).

Reduction of $\Delta \Psi_{m}$ in honokiol-induced cell death. The present study further investigated the $\Delta \Psi \mathrm{m}$ in honokiol-treated bladder cancer cells. By using the DiOC6 staining assay, it was identified that honokiol induced transient hyperpolarization of the mitochondrial membrane in bladder cancer cells (Fig. 5). Higher doses of honokiol $(50$ and $75 \mu \mathrm{M})$ induced a significant increase in $\Delta \Psi \mathrm{m}(161 \pm 23.7$ and $185 \pm 22.8 \%$, respectively) compared with the control group after $24 \mathrm{~h}$ of incubation $(\mathrm{P}<0.05$; Fig. 5).

Caspase-3/7 activation in honokiol-induced apoptotic cell death. Finally, the caspase activities in honokiol-treated bladder cancer cells were investigated. As presented in Fig. 6, caspase-3/7 was significantly activated in high-dose honokiol-treated bladder cancer cells in comparison with untreated control cells after $36 \mathrm{~h}$ of incubation $(\mathrm{P}<0.05)$. These results indicated that the intrinsic apoptotic pathway may have a critical role in honokiol-triggered apoptosis in bladder cancer cells.

\section{Discussion}

Flow cytometry is a well-known laser-based technology for cell characterization, functional assays and disease diagnosis 
A

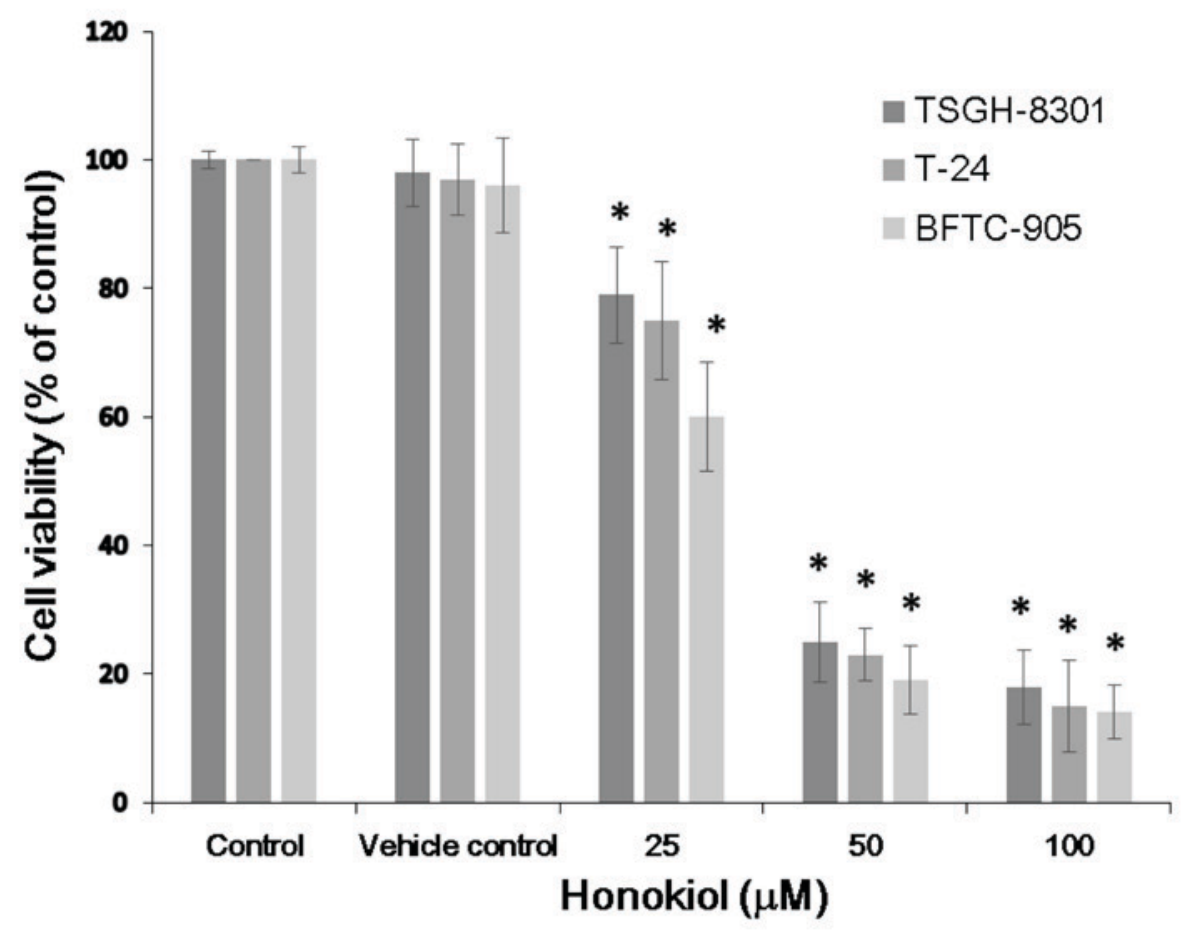

B
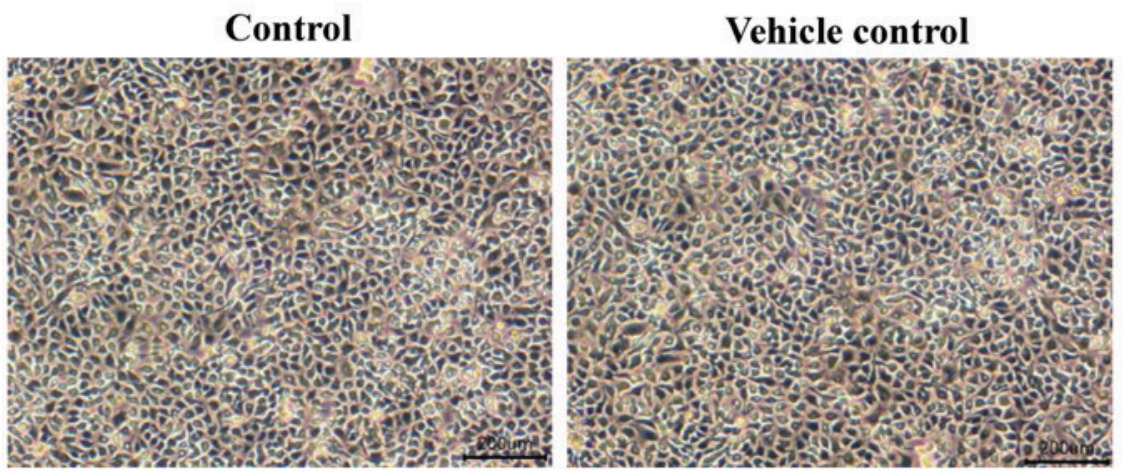

$25 \mu \mathrm{M}$

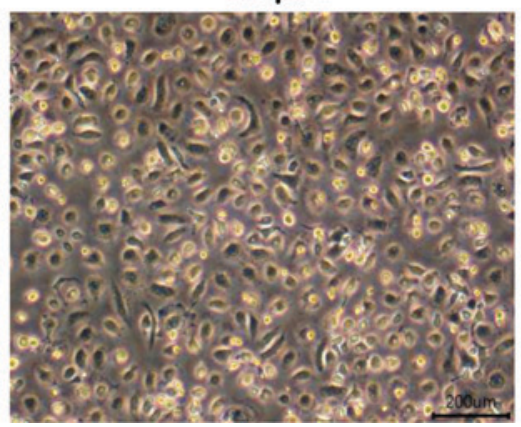

$\mathbf{5 0} \mu \mathbf{M}$

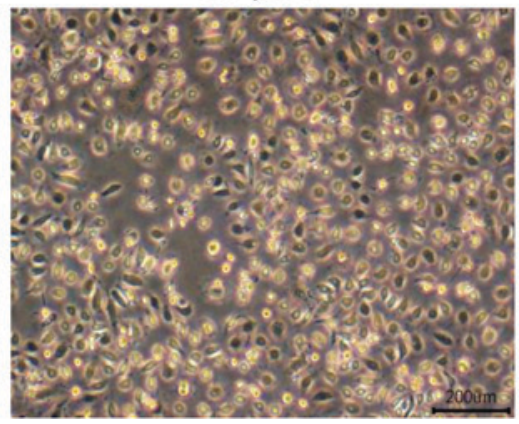

$75 \mu \mathrm{M}$

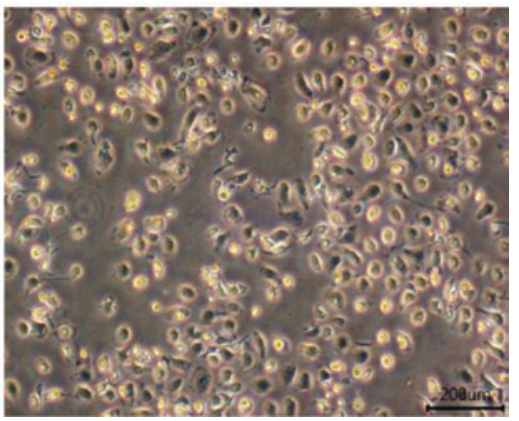

Figure 1. Effects of honokiol on the viability of bladder cancer cells. (A) The bladder cancer cell lines TSGH-8301, T-24 and BFTC-905 were treated with various concentrations of honokiol for $72 \mathrm{~h}$. ${ }^{\mathrm{P}}<0.05 \mathrm{vs}$. control group. (B) Morphology of BFTC- 905 cells treated with indicated concentrations of honokiol for $48 \mathrm{~h}$ (scale bar, $200 \mu \mathrm{m})$. Upper left panel, control group; upper right panel, vehicle control group (0.05\% dimethyl sulfoxide); lower left panel, $25 \mu \mathrm{M}$ honokiol group; lower central panel, $50 \mu \mathrm{M}$ honokiol group; lower right panel, $75 \mu \mathrm{M}$ honokiol group.

utilized in basic research and for clinical examinations. Thus, it is a convenient and effective method for clinicians to investigate the molecular mechanisms of specific targets. Flow cytometric immunophenotyping is another sensitive, reproducible and low-cost quantitative auxiliary diagnostic technique with a fast turnaround time, particularly for the detection and classification of hematolymphoid neoplasms (22). DNA indexing, also named the Vindelov method, is recommended for single-parameter 
A

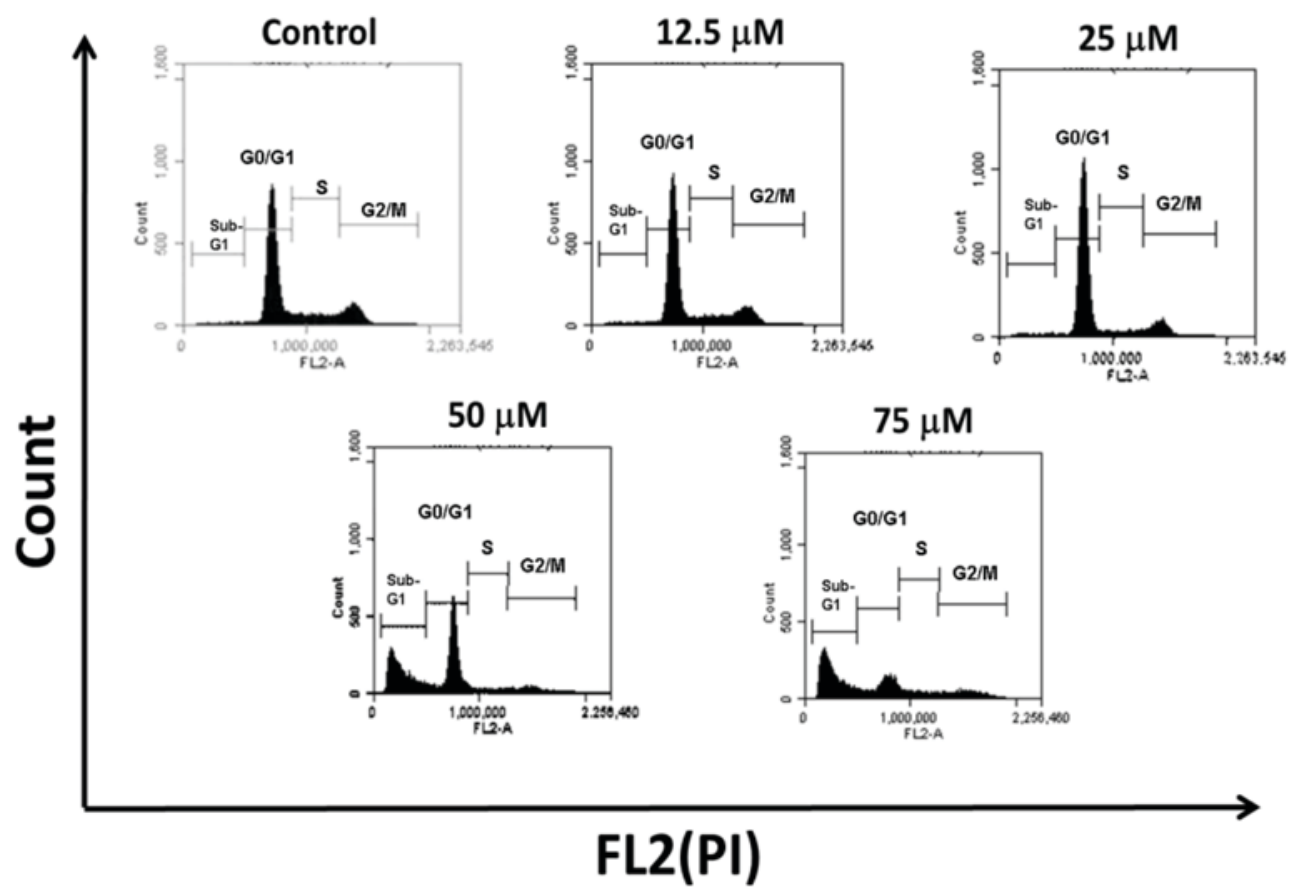

B

C
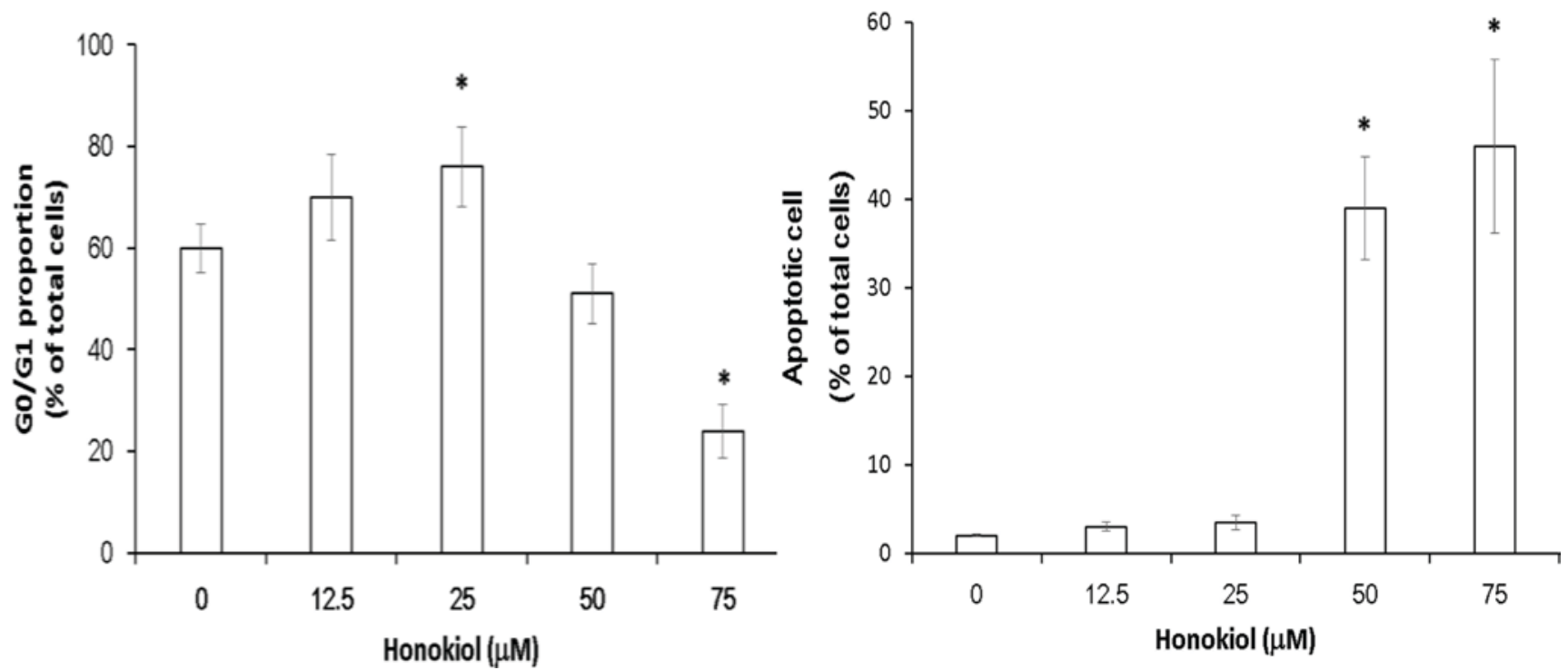

Figure 2. Effects of honokiol on BFTC-905 cell cycle progression. (A) Cells were treated with various concentrations of honokiol for $72 \mathrm{~h}$ and then harvested for PI staining, followed by flow cytometric analysis. (B) Quantification of the number of G0/G1 cells, and (C) apoptotic cells at sub-G1 phase. Values are expressed as the mean fluorescence intensity \pm standard error of the mean from three independent experiments. ${ }^{*} \mathrm{P}<0.05$ vs. control group. PI, propidium iodide.

DNA studies by flow cytometry on fresh as well as frozen clinical samples, and various novel multicolour staining techniques for cell characterization and identification by flow cytometry have been developed for clinical application (23). Magnolia officinalis is a plant used in traditional Chinese and Japanese medicine that provides multiple benefits. In the present study, the anti-cancer properties of honokiol, a bioactive component derived from Magnolia officinalis, on bladder cancer cells were 
A

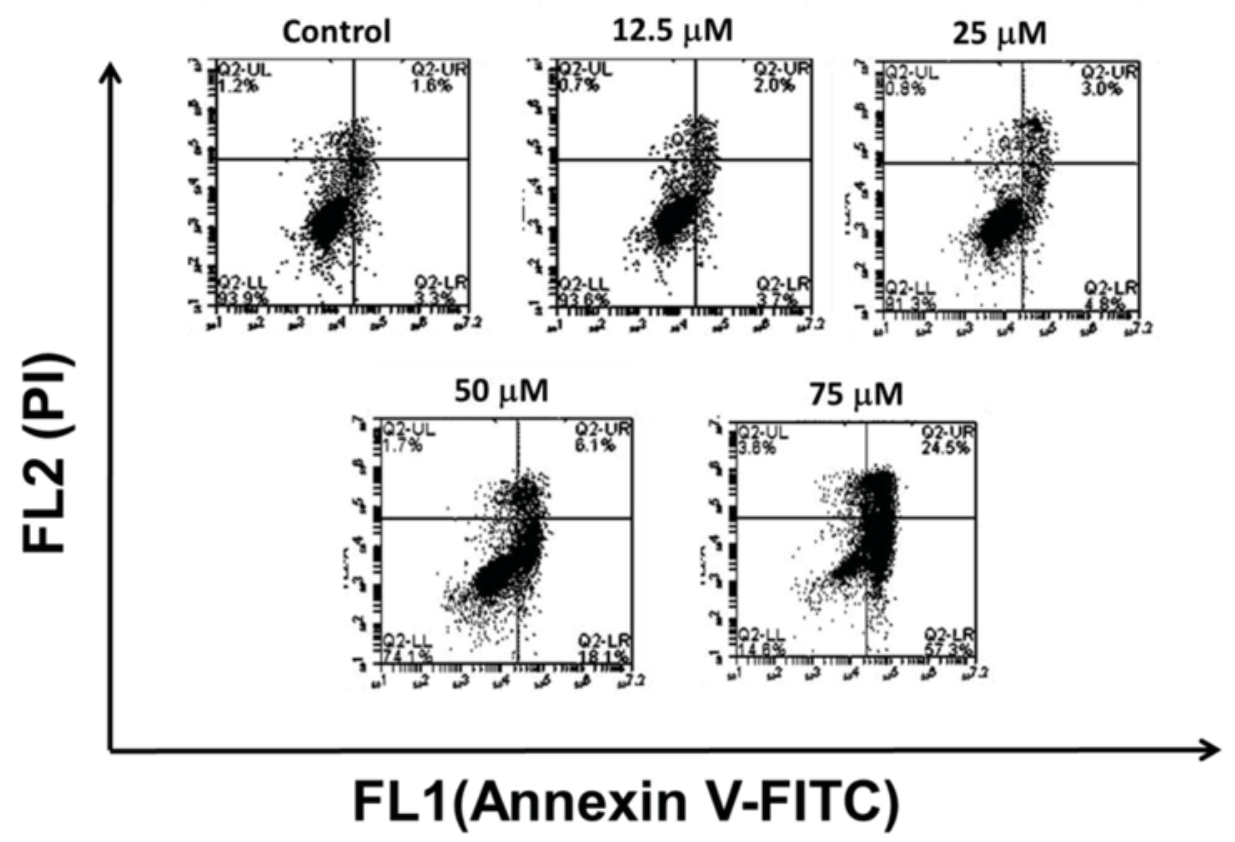

B

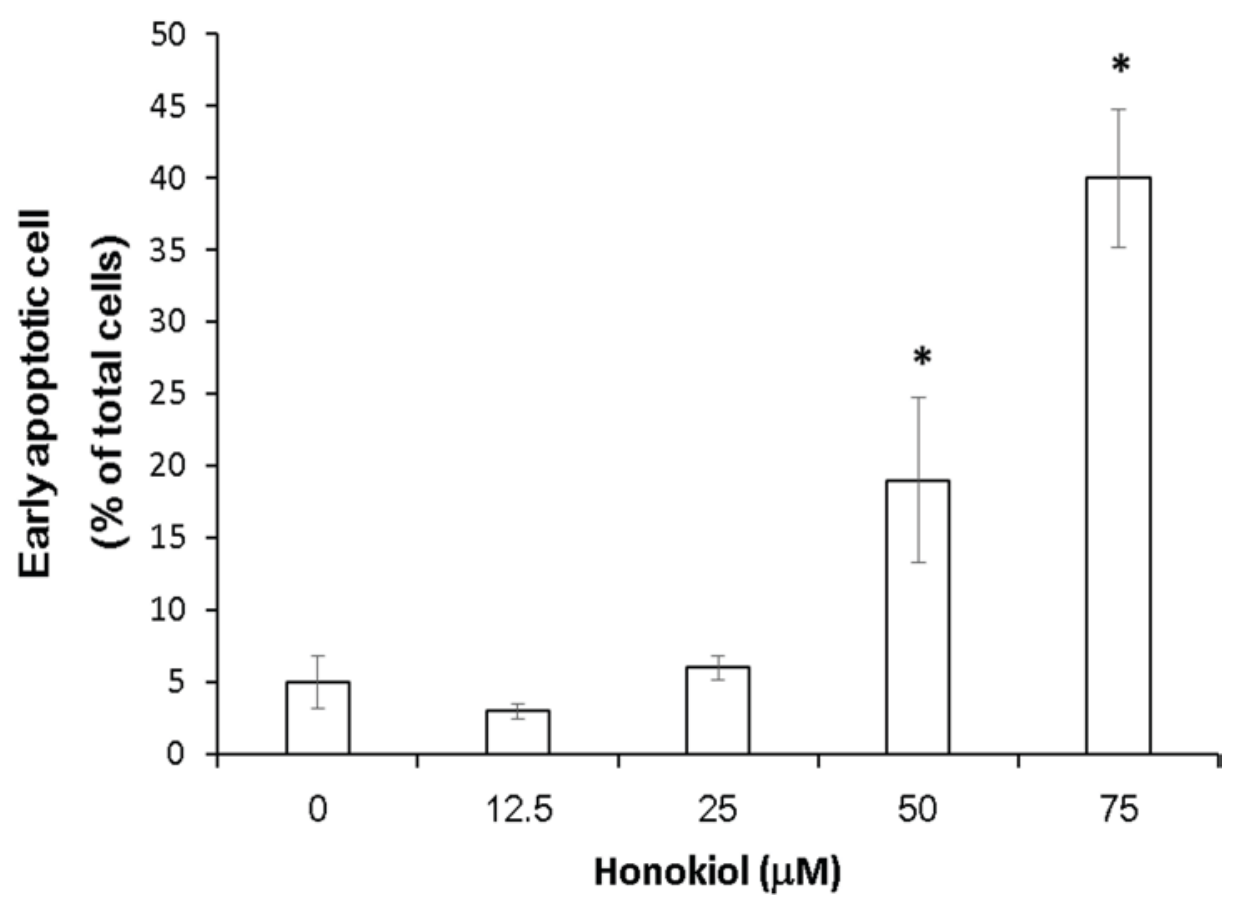

Figure 3. Effects of honokiol on apoptotic cell death of BFTC-905 cells. (A) The cells were treated with various concentrations of honokiol for $48 \mathrm{~h}$, harvested for Annexin V-FITC/PI double staining and then analyzed by flow cytometry. (B) Early apoptotic cells identified in Q2-LR. Values are expressed as the mean fluorescence intensity \pm standard error of the mean from three independent experiments. " $\mathrm{P}<0.05$ vs. control group. PI, propidium iodide; FITC, fluorescein isothiocyanate; UL, upper left; UR, upper right; LL, lower left; LR, lower right.

investigated by flow cytometric technology. It has been previously reported that honokiol reduced bladder tumor growth by blocking the enhancer of zeste 2 polycomb repressive complex
2 subunit/microRNA-143 axis and inhibited bladder cancer cell invasion through repressing SRC-3 expression and epithelial-to-mesenchymal transition $(19,20)$. In the present study, the 


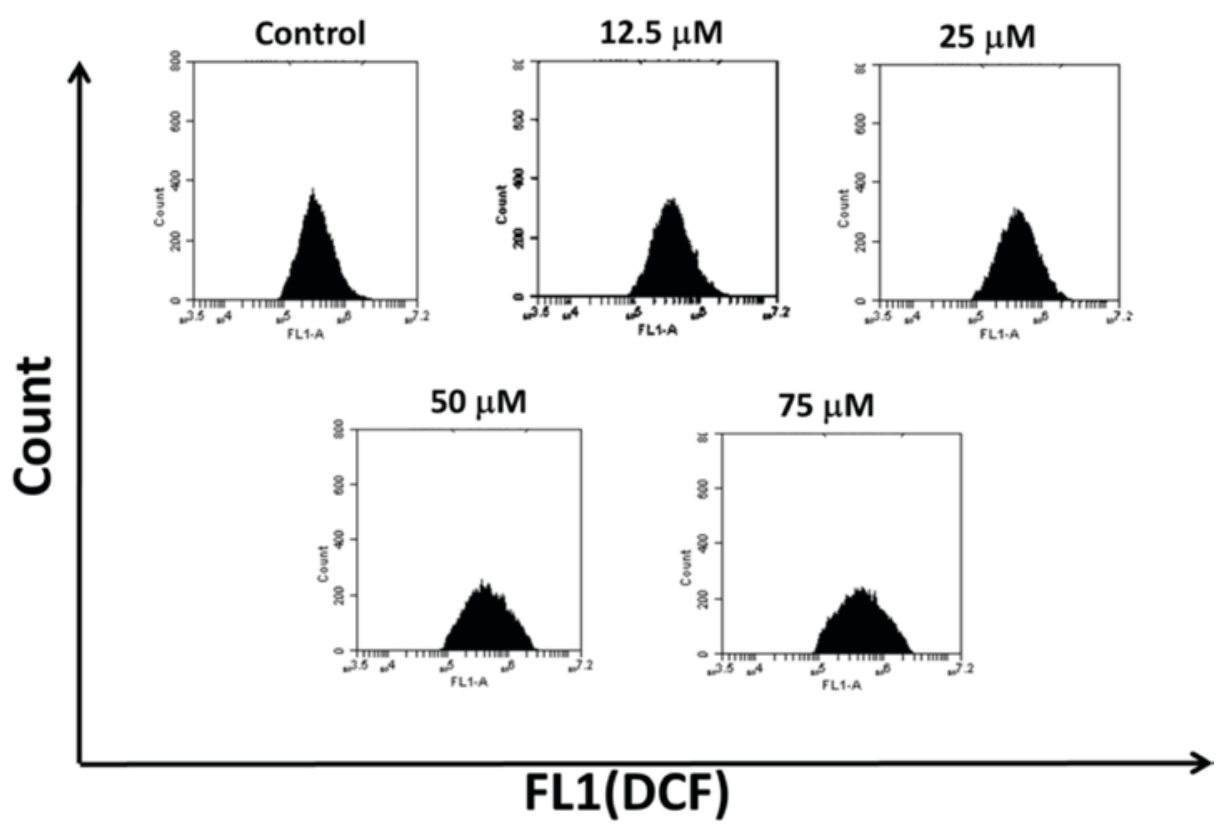

B

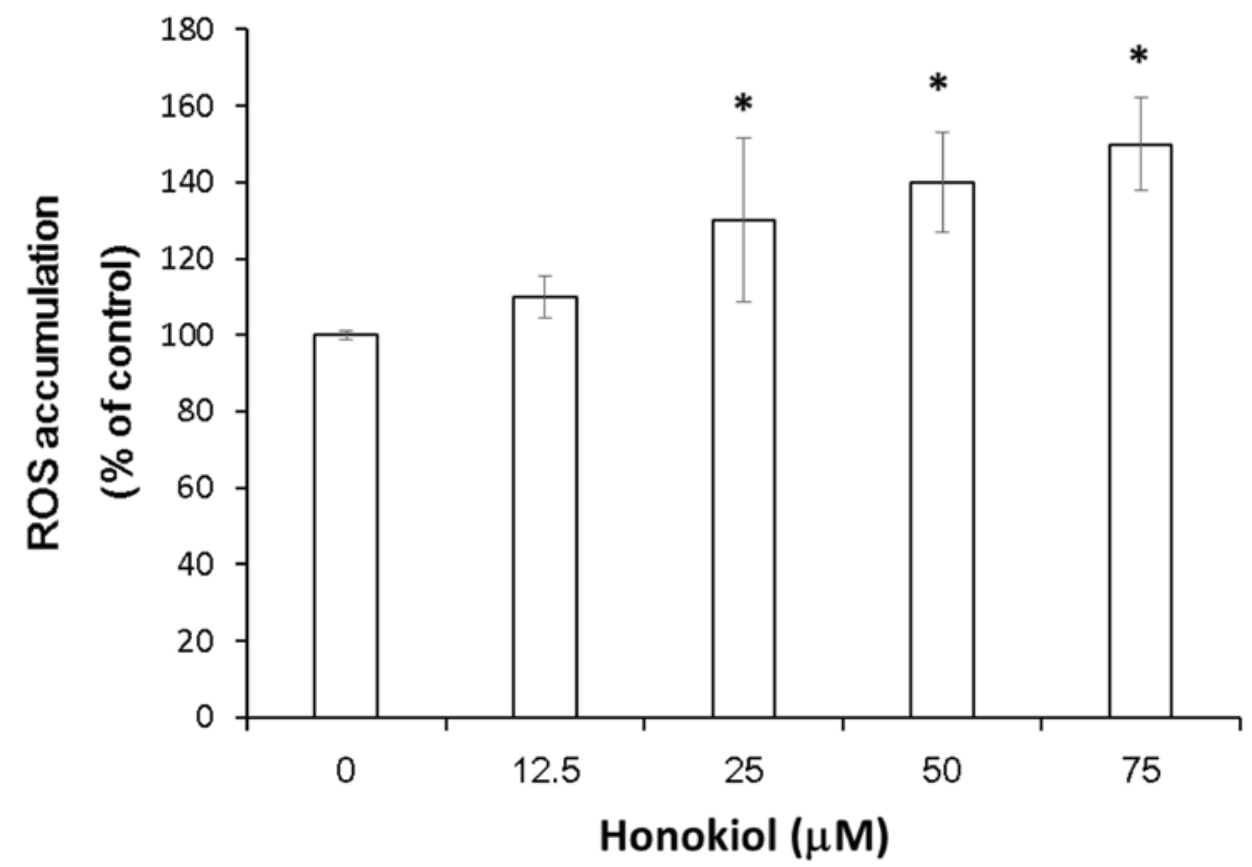

Figure 4. Effects of honokiol on ROS accumulation in BFTC-905 cells. (A) The cells were treated with various concentrations of honokiol for $24 \mathrm{~h}$, harvested for 2',7'-dichlorodihydrofluorescein diacetate staining and then analyzed by flow cytometry. (B) Quantified ROS accumulation. Values are expressed as the mean fluorescence intensity \pm standard error of the mean from three independent experiments. " $\mathrm{P}<0.05$ vs. control group. ROS, reactive oxygen species; DCF, 2',7'-dichlorofluorescein.

cytotoxicity of honokiol against various human bladder cancer cell lines was first assessed. An SRB cell viability assay was performed to evaluate the cytotoxic effect of honokiol on three human transitional cell carcinoma cell lines. It was revealed that the human BFTC-905 cell line with grade-III malignancy exhibited the highest sensitivity to honokiol. Therefore, the 
A

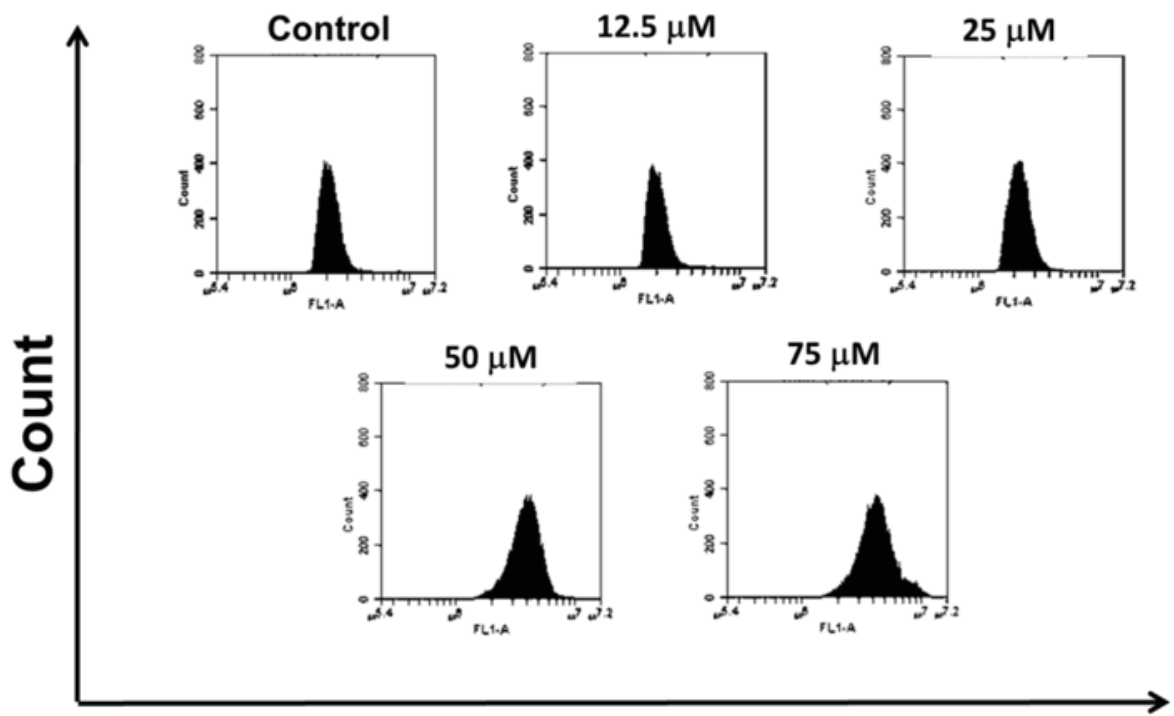

FL1(DiOC6)

B

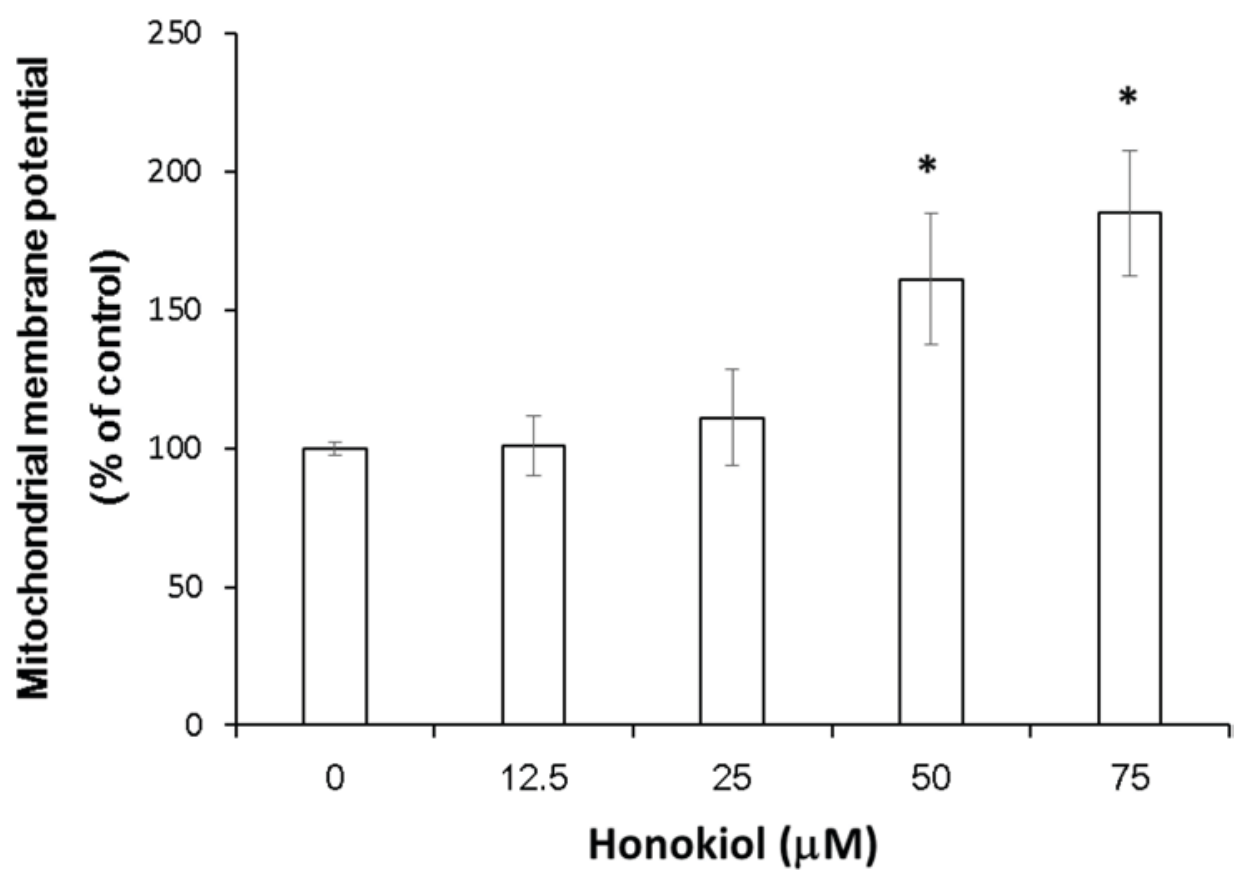

Figure 5. Effects of honokiol on the mitochondrial membrane potential of BFTC-905 cells. (A) The cells were treated with various concentrations of honokiol for $24 \mathrm{~h}$, harvested for DiOC6 staining and then analyzed by flow cytometry. (B) Quantification of the mitochondrial membrane potential. Values are expressed as the mean fluorescence intensity \pm standard error of the mean from three independent experiments. " $\mathrm{P}<0.05$ vs. control group. DiOC6, 3,3'-dihexyloxacarbocyanine iodide.

subsequent experiments were performed with this cell line to investigate the mechanisms of honokiol-induced cytotoxicity. It was revealed that honokiol exerted its anti-cancer activity through induction of growth arrest, apoptosis and necrosis. Low-dose honokiol $(<25 \mu \mathrm{M})$ induced cell cycle arrest in $\mathrm{G}_{0} / \mathrm{G}_{1}$ phase, while high-dose honokiol $(50$ and $75 \mu \mathrm{M})$ induced 


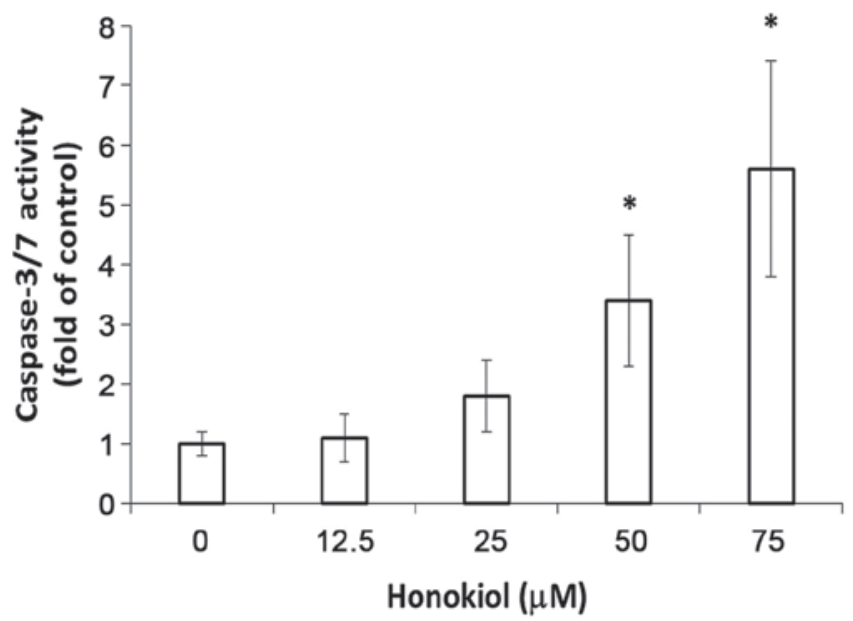

Figure 6. Effects of honokiol on the caspase-3/7 activity of BFTC-905 cells. The cells were treated with the indicated concentrations of honokiol for $36 \mathrm{~h}$ and then harvested for the caspase activity assay. The cell lysates were incubated with DEVD-AFC for $1 \mathrm{~h}$, and the samples were analyzed in a fluorometer equipped with a 400-nm excitation filter and 505-nm emission filter. The fold-increase in caspase-3/7 activity was determined by comparing the results for the treated group with the levels of the untreated control. Values are expressed as the mean fluorescence intensity \pm standard error of the mean from three independent experiments. ${ }^{*} \mathrm{P}<0.05$ vs. control group. DEVD-AFC, DEVD-7-amino-4-trifluoromethyl coumarin.

apoptotic cell death, and further induced necrotic cell death at concentrations of $>100 \mu \mathrm{M}$ (data not shown). It has been previously revealed that honokiol treatment had no obvious cytotoxicity on kidney epithelial cells at $<15 \mu \mathrm{M}$ and honokiol $(50 \mu \mathrm{M})$ also protected the pancreatic $\beta$ cells from intermittent hypoxia and high glucose-induced cytotoxicity (24). Honokiol also acts as a potent neuroprotective agent against the cognitive defects after traumatic brain injury in rats (25). It has also been reported that honokiol had an obvious cytotoxic effect on murine hepatic AML12 cells at concentrations of up to $40 \mu \mathrm{M}$, while at lower concentrations $(<20 \mu \mathrm{M})$, honokiol exerted a cytoprotective effect against tert-butyl hydroperoxide-induced oxidative stress (26). Recently, it has been reported that honokiol acts as a potential antagonist against forkhead box M1, which may partially explain for its anti-cancer activity in several solid cancer cell lines (27). Based on the above, honokiol may have celland dosage-dependent anti-cancer and cytoprotective effects by targeting diverse pathways. The dosage-dependent effects of honokiol revealed in these in vitro studies may serve as a reference for animal in vivo studies in the future. To the best of our knowledge, the present study was the first to provide evidence of honokiol-induced apoptotic death of bladder cancer cells. Based on the present results, it is likely that honokiol induces cell cycle arrest and apoptotic cell death by causing oxidative burst and hyperpolarization of the mitochondrial membrane. It has been previously revealed that honokiol induced apoptosis/autophagy of human glioma cells by ROS-mediated signaling transduction pathways and enhanced caspase activation $(15,16)$. In line with this, the present study also indicated that honokiol induced significant ROS accumulation and stimulated caspase-3/7 activation. Honokiol may thus have an impact on several molecular pathways and have various biological functions. The $\Delta \Psi \mathrm{m}$ is a decisive factor that determines the cell fate between survival and death (28). Of note, to the best of our knowledge, the present study was the first to indicate that honokiol induced hyperpolarization of the mitochondrial membrane in bladder cancer cells. It has been proposed that under pro-apoptotic conditions, the closed state of the voltage-dependent anion channel may bring about a transient mitochondrial membrane hyperpolarization, followed by osmotic imbalance, outer membrane rupture, release of the intermembrane space proteins and ultimately cell death (29). The effects of honokiol-induced dysfunction of mitochondria may be exerted in a time-, dosage- and cell type-dependent manner. Although the present study provided critical insight into the apoptosis-inducing effect of honokiol on bladder cancer cells via hyperpolarization of mitochondria and the induction of ROS burst, the synergistic efficacy of honokiol in combination with chemoradiation-based therapies used in bladder cancer treatment requires assessment by further studies. Of note, a limitation of the present study was the lack of cell viability assessment of honokiol-treated normal bladder cells as a safety evaluation. However, a study by Hua et al (30) revealed that only a high concentration $(100 \mu \mathrm{M})$ of honokiol suppressed the proliferation of normal colon epithelial cells.

In conclusion, the present study suggested that honokiol has potential use as an adjuvant for urothelial bladder cancer treatment. In the future, the detailed underlying mechanisms require to be elucidated and the efficacy requires evaluation in pre-clinical in vivo studies.

\section{Acknowledgements}

The authors would like to thank Miss Tsu-Yi Yi (Cancer Center, Wan Fang Hospital, Taipei, Taiwan) for her technical support.

\section{Funding}

The present study was supported by grants from the Research Fund of the Department of Medical Research, China Medical University Hospital (grant nos. DMR-107-153 and DMR-CELL-1809) and the National Science Council of Taiwan (grant no. NSC 105-2320-B-039-068).

\section{Availability of data and materials}

The datasets used and/or analyzed in the present study are available from the corresponding author on reasonable request.

\section{Authors' contributions}

CHH, CJY, GML and PHS made contributions to the conception and design of the study and prepared the manuscript. $\mathrm{CHH}, \mathrm{CJY}$ and PHS performed the experiments and data analysis. GML, LML and JWP reviewed the literature and interpreted the results. $\mathrm{CHH}$ and PHS revised the manuscript. All authors read and approved the final manuscript.

\section{Ethics approval and consent to participate}

Not applicable.

\section{Patient consent for publication}

Not applicable. 


\section{Competing interests}

The authors declare that they have no competing interests.

\section{References}

1. American Cancer Society. Cancer Facts \& Figures, 2018.

2. Cancer Prevention Group: Annual Report of Taiwan Cancer Registry for 2016. December 27, 2018 (https://www.hpa.gov.tw/ Pages/Detail.aspx?nodeid=269\&pid=10227).

3. Huang CY, Lin YC, Shiue HS, Chen WJ, Su CT, Pu YS, Ao PL and Hsueh YM: Comparison of arsenic methylation capacity and polymorphisms of arsenic methylation genes between bladder cancer and upper tract urothelial carcinoma. Toxicol Lett 295: 64-73, 2018.

4. Boulanger M, Tual S, Lemarchand C, Guizard AV, Velten M, Marcotullio E, Baldi I, Clin B and Lebailly PP: Agricultural exposure and risk of bladder cancer in the AGRIculture and CANcer cohort. Int Arch Occup Environ Health 90: 169-178, 2017.

5. Mendez WM Jr, Eftim S, Cohen J, Warren I, Cowden J, Lee JS and Sams R: Relationships between arsenic concentrations in drinking water and lung and bladder cancer incidence in U.S. counties. J Expo Sci Environ Epidemiol 27: 235-243, 2017.

6. Shibata A, Ohneseit PF, Tsai YC, Spruck CH III, Nichols PW, Chiang HS, Lai MK and Jones PA: Mutational spectrum in the p53 gene in bladder tumors from the endemic area of black foot disease in Taiwan. Carcinogenesis 15: 1085-1087, 1994.

7. NNational Comprehensive Cancer Network (NCCN) Clinical Practice Guidelines in Oncology (NCCN GuidelinesOे). Bladder cancer. Version 2.2018. February 7, 2018 (https://oncolife.com. ua/doc/nccn/Bladder_Cancer.pdf)

8. Shelley MD, Mason MD and Kynaston H: Intravesical therapy for superficial bladder cancer: A systematic review of randomised trials and meta-analyses. Cancer Treat Rev 36: 195-205, 2010.

9. Koga F, Takemura $\mathrm{K}$ and Fukushima $\mathrm{H}$ : Biomarkers for predicting clinical outcomes of chemoradiation-based bladder preservation therapy for muscle-invasive bladder cancer. Int J Mol Sci 19: E2777, 2018

10. Rauf A, Patel S, Imran M, Maalik A, Arshad MU, Saeed F, Mabkhot YN, Al-Showiman SS, Ahmad N and Elsharkawy E: Honokiol: An anticancer lignan. Biomed Pharmacother 107: 555-562, 2018

11. Zubair H, Azim S, Ahmad A, Khan MA, Patel GK, Singh S and Singh AP: Cancer chemoprevention by phytochemicals: Nature's healing touch. Molecules 22: E395, 2017.

12. Lee YJ, Lee YM, Lee CK, Jung JK, Han SB and Hong JT: Therapeutic applications of compounds in the magnolia family. Pharmacol Ther 130: 157-176, 2011.

13. Kumar A, Kumar Singh U and Chaudhary A: Honokiol analogs: A novel class of anticancer agents targeting cell signaling pathways and other bioactivities. Future Med Chem 5: 809-829, 2013.

14. Prasad R and Katiyar SK: Honokiol, an active compound of Magnolia plant, inhibits growth, and progression of cancers of different organs. Adv Exp Med Biol 928: 245-265, 2016.
15. Chio CC, Chen KY, Chang CK, Chuang JY, Liu CC, Liu SH and Chen RM: Improved effects of honokiol on temozolomide-induced autophagy and apoptosis of drug-sensitive and -tolerant glioma cells. BMC Cancer 18: 379, 2018.

16. Chio CC, Tai YT, Mohanraj M, Liu SH, Yang ST and Chen RM. Honokiol enhances temozolomide-induced apoptotic insults to malignant glioma cells via an intrinsic mitochondrion-dependent pathway. Phytomedicine 49: 41-51, 2018.

17. Lai IC, Shih PH, Yao CJ, Yeh CT, Whang-Peng J,Lui TN, Chuang SE, Hu TS, Lai TY and Lai GM: Elimination of cancer stem-like cells and potentiation of temozolomide sensitivity by Honokiol in glioblastoma multiforme cells. PLoS One 10: e0114830, 2015.

18. Chang MT, Lee SP, Fang CY, Hsieh PL, Liao YW, Lu MY, Tsai LL, Yu CC and Liu CM: Chemosensitizing effect of honokiol in oral carcinoma stem cells via regulation of IL-6/Stat3 signaling. Environ Toxicol 33: 1105-1112, 2018.

19. Zhang Q, Zhao W, Ye C, Zhuang J, Chang C, Li Y, Huang X, Shen L, Li Y, Cui Y, et al: Honokiol inhibits bladder tumor growth by suppressing EZH2/miR-143 axis. Oncotarget 6: 37335-37348, 2015.

20. Shen L, Zhang F, Huang R, Yan J and Shen B: Honokiol inhibits bladder cancer cell invasion through repressing SRC-3 expression and epithelial-mesenchymal transition. Oncol Lett 14: 4294-4300, 2017.

21. Vichai V and Kirtikara K: Sulforhodamine B colorimetric assay for cytotoxicity screening. Nat Protoc 1: 1112-1116, 2006.

22. Monappa V, Reddy SM and Kudva R: Hematolymphoid neoplasms in effusion cytology. Cytojournal 15: 15, 2018.

23. Danova M, Torchio M, Comolli G, Sbrana A, Antonuzzo A and Mazzini G: The role of automated cytometry in the new era of cancer immunotherapy. Mol Clin Oncol 9: 355-361, 2018.

24. Li CG, Ni CL, Yang M, Tang YZ, Li Z, Zhu YJ, Jiang ZH, Sun B and $\mathrm{Li} \mathrm{CJ}$ : Honokiol protects pancreatic beta cell against high glucose and intermittent hypoxia-induced injury by activating Nrf2/ARE pathway in vitro and in vivo. Biomed Pharmacother 97: 1229-1237, 2018

25. Wang H, Liao Z, Sun X, Shi Q, Huo G, Xie Y, Tang X, Zhi X and Tang Z: Intravenous administration of Honokiol provides neuroprotection and improves functional recovery after traumatic brain injury through cell cycle inhibition. Neuropharmacology 86: 9-21, 2014

26. Liu JX, Shen SN, Tong Q, Wang YT and Lin LG: Honokiol protects hepatocytes from oxidative injury through mitochondrial deacetylase SIRT3. Eur J Pharmacol 834: 176-187, 2018.

27. Halasi M, Hitchinson B, Shah BN, Váraljai R, Khan I, Benevolenskaya EV, Gaponenko V, Arbiser JL and Gartel AL: Honokiol is a FOXM1 antagonist. Cell Death Dis 9: 84, 2018.

28. Kroemer G, Galluzzi L and Brenner C: Mitochondrial membrane permeabilization in cell death. Physiol Rev 87: 99-163, 2007.

29. Green DR and Llambi F: Cell death signaling. Cold Spring Harb Perspect Biol 7: a006080, 2015.

30. Hua H, Chen W, Shen L, Sheng Q and Teng L: Honokiol augments the anti-cancer effects of oxaliplatin in colon cancer cells. Acta Biochim Biophys Sin (Shanghai) 45: 773-779, 2013. 